\title{
Gene pool sharing and genetic bottleneck effects in subpopulations of Eschweilera ovata (Cambess.) Mart. ex Miers (Lecythidaceae) in the Atlantic Forest of southern Bahia, Brazil
}

\author{
Alesandro S. Santos ${ }^{1}$, Daniela B. Borges ${ }^{2}$, Caio V. Vivas ${ }^{2}$, Cassio Van Den Berg ${ }^{3}$, Polliana S. Rodrigues ${ }^{4}$, \\ Roberto Tarazi ${ }^{5}$ and Fernanda Amato Gaiotto ${ }^{4}$ ii \\ ${ }^{1}$ Laboratório de Ecologia Aplicada à Conservação, Pós-Graduação em Ecologia e Conservação da \\ Biodiversidade, Universidade Estadual de Santa Cruz, Ilhéus, BA, Brazil. \\ ${ }^{2}$ Pós-Graduação em Genética e Biologia Molecular, Universidade Estadual de Santa Cruz, Ilhéus, BA, \\ Brazil. \\ ${ }^{3}$ Universidade Estadual de Feira de Santana, Departamento de Ciências Biológicas, Feira de Santana, BA, \\ Brazil. \\ ${ }^{4}$ Laboratório de Marcadores Moleculares, Centro de Biotecnologia e Genética, Universidade Estadual de \\ Santa Cruz, Ilhéus, BA, Brazil. \\ ${ }^{5}$ BASF Discovery Breeder, Trindade, GO, Brazil.
}

\begin{abstract}
Forest loss and fragmentation are the main threats to the maintenance of the Atlantic Forest, an important global biodiversity hotspot. Because of the current critical level of deforestation, ecological corridors are needed to facilitate species dispersion and gene flow among fragments. This study was conducted to investigate the genetic variability and gene pool sharing of Eschweilera ovata in five forest remnants in southern Bahia, Brazil using nuclear simple sequence repeat (nSSR) and plastid simple sequence repeat (cpSSR) microsatellite markers. cpSSR marker analysis revealed the domains of four haplotypes, showing that $80 \%$ of the individuals had only four maternal origins, reflecting a founder effect and/or genetic bottleneck. The results of cpSSR and nSSR analyses indicated moderate genetic diversity, particularly in conservation units with full protection, which showed the best parameters of all areas evaluated. Another indication of the susceptibility of these populations to forest loss and fragmentation was the strong genetic bottleneck observed. In contrast, genetic structure analyses $\left(F_{\mathrm{ST}}\right.$ and discriminant analysis of principal components) revealed gene pool sharing between the subpopulations, which may reflect the historical gene flow that occurred before forest fragmentation.
\end{abstract}

Keywords: Functional connectivity, tree species, chloroplast, founder effect, simple sequence repeat development.

Received: June 13, 2018; Accepted: January 28, 2019.

\section{Introduction}

The Atlantic Forest in the east of Brazil is an important center of endemism associated with high species richness of several taxa, particularly tree species (Thomas et al., 1998; Myers et al., 2000; Martini et al., 2007; MurraySmith et al., 2008). Despite its great importance for biodiversity conservation, this phytogeographical domain has been reduced to approximately $11-16 \%$ of its original area (Ribeiro et al., 2009). This anthropogenic forest reduction represents one of the main threats to the permanence of species in this environment by reducing resources and increas-

Send correspondence to Fernanda Amato Gaiotto: Laboratório de Marcadores Moleculares, Centro de Biotecnologia e Genética, Universidade Estadual de Santa Cruz, Rodovia Ilhéus-Itabuna, km 16, 45662-900 Ilhéus, BA, Brazil. E-mail: gaiotto@uesc.br. ing the risks of population extinctions (Pessoa et al., 2016; Benchimol et al., 2017). Additionally, the negative effects of forest reduction on biodiversity can be potentialized through interactions that cause structural isolation and decrease species dispersal and gene flow among forest remnants (Tabarelli et al., 2004; Pardini et al., 2010; Lima and Mariano-Neto, 2014).

Considering the conservation scope and current state of the reduction and fragmentation of the Atlantic Forest, it is important to establish ecological corridors between forest remnants (MMA, 2008) to allow the dispersion of species (Damschen et al., 2006). Enabling gene flow between fragments and corridors decreases the deleterious effects caused by isolation and the reduction of forest area that decrease populations and their genetic diversity, thus increas- 
ing the risk of local extinctions over time (Carvalho et al., 2015).

In the last few decades, genetic studies using a conservationist approach have mainly employed molecular markers such as microsatellites to evaluate the variability and distribution of the genetic diversity of tree species (Gaiotto et al., 2003; Santos et al., 2016; Carvalho et al., 2017; Torres-Florez et al., 2017). Some of these studies used microsatellite markers with biparental and uniparental inheritance patterns to determine historical colonization patterns and functional connections among tree species populations (Martins et al., 2011; Zhang et al., 2012). Several studies revealed founder effects in plant populations by using chloroplastidial microsatellites (cpSSRs), which show maternal inheritance in most species of angiosperms and act as functionally haploid and non-recombinant markers (Corriveau and Coleman, 1988; Weising and Gardner, 1999; Parducci et al., 2001; Li et al., 2012; Tong et al., 2013). Additionally, studies combining nuclear and chloroplast microsatellite markers have shown similar results, suggesting that these approaches are complementary (Zhang et al., 2012; Tóth et al., 2017).

Because of the current critical state of the reduction and fragmentation of the Atlantic Forest, we evaluated the genetic variability and gene pool sharing of a tree species, Eschweilera ovata (Cambess.) Mart. ex Miers (Lecythidaceae), in five forest remnants in southern Bahia, Brazil, using cpSSR and nSSR markers. These remnants are in a region with high endemism and plant richness where efforts are underway to implement ecological corridors that connect forest fragments and conservation units (Fonseca et al., 2004). This tree species has a large occurrence (Atlantic Forest, Amazon Forest, Cerrado and Caatinga) and shows a zoochoric syndrome of seed dispersal and pollen. Additionally, it was suggested that this species can be used to promote the recovery of degraded areas. E. ovata is also economically exploited to make the berimbau, a musical instrument used in capoeira orchestras, a cultural symbol of the state of Bahia, Brazil (Lorenzi, 1998). In this study, we tested the following hypotheses: (1) The subpopulations of E. ovata have high genetic diversity in both molecular markers, considering the wide occurrence and density of the species; and (2) The subpopulations still share a gene pool, reflecting functional connectivity prior to forest loss and fragmentation.

\section{Material and Methods}

\section{Study area}

The study was conducted in five areas in southern Bahia, Brazil, a portion of the Atlantic Forest that is considered a priority for conservation actions due to its biological importance (Thomas et al., 1998; Martini et al., 2007). Using ArcGIS (10.2), we created a map of the study region that includes all areas and forest remnants (Figure 1). Four of the five locations are inside a protected area (PA): Reserva Biológica de Una (ReBio) covering 11,400 hectares in Una; Parque Municipal Boa Esperança (PMBE) covering 437 hectares in the urban area of Ilhéus; Reserva Particular do Patrimônio Natural (RPPN) Mãe da Mata covering 13 hectares in Ilhéus; and RPPN Capitão covering 660 hectares in Itacaré. The fifth area corresponds to an arboreal restinga (Restinga) between the PMBE and ReBio in Ilhéus, which is not in a PA.

In each study area, we collected leaf samples from 15 E. ovata adult individuals for genetic analysis and georeferenced the trees using GPS (GPS Garmin Map $62 \mathrm{~s}$, Olathe, KS, USA). Sampling was performed to cover as much of each area as possible while avoiding the sampling of individuals geographically close to each other to reduce the chances of kinship between them and to sample the genetic pool of each collection area (distance varying between 10 and 2,000 $\mathrm{m}$ between individuals sampled). Estimates of the population genetics parameters are influenced by number and frequency of informative alleles (frequency $\geq 0.05$ ) (Hale et al., 2012). Thus, to evaluate the accuracy of estimated allelic frequencies for the 15 individuals sampled in each of the four subpopulations using nSSR markers, we calculated the allele frequencies and mean allelic pattern (number of different alleles, number different alleles with a frequency $\geq 5 \%$ and Shannon's information index) with standard deviation using the GenAlex 6.5 program (Peakall and Smouse, 2012). If the number of individuals influenced the estimates mentioned above, great heterogeneity in these measures would be observed among the populations as a reflection of sampling error.

\section{DNA extraction, development of specific microsatellite primers, and genotyping with $\mathrm{cpSSR}$ and nSSR}

DNA was obtained according to the CTAB protocol (Doyle and Doyle, 1987) and the quantification was performed in agarose gels $(0.8 \%)$.

An enriched library was obtained by hybridization with $(\mathrm{CT})_{8}$ and $(\mathrm{GT})_{8}$ biotinylated probes, and positive fragments for the microsatellites were amplified and sequenced on an ABI 3100 genetic analyzer (Applied Biosystems, Foster City, CA, USA). We used Primer3 software (Untergasser et al., 2007) to design primer pairs.

To characterize the new nuclear microsatellite marker set (nSSR) and perform genetic analysis of the populations, we used individual DNA sampled from four subpopulations (ReBio, MM, Cap, and AR) for a total of 60 trees. PCR samples contained $7.5 \mathrm{ng}$ of genomic DNA, $10 \mu \mathrm{L}$ of Top Taq Master Mix kit (Qiagen), $0.8 \mu \mathrm{M}$ of primer reverse, $0.4 \mu \mathrm{M}$ of forward primer, and $0.16 \mu \mathrm{M}$ of M13 tail (CAC GACGTTGTAAAACGA) labeled with a fluorochrome (6-FAM, VIC, PET, or NED, Applied Biosystems, Foster City, CA, USA). The amplification reaction was run in a Veriti 96-Well Thermal Cycler (Applied Biosystems). 


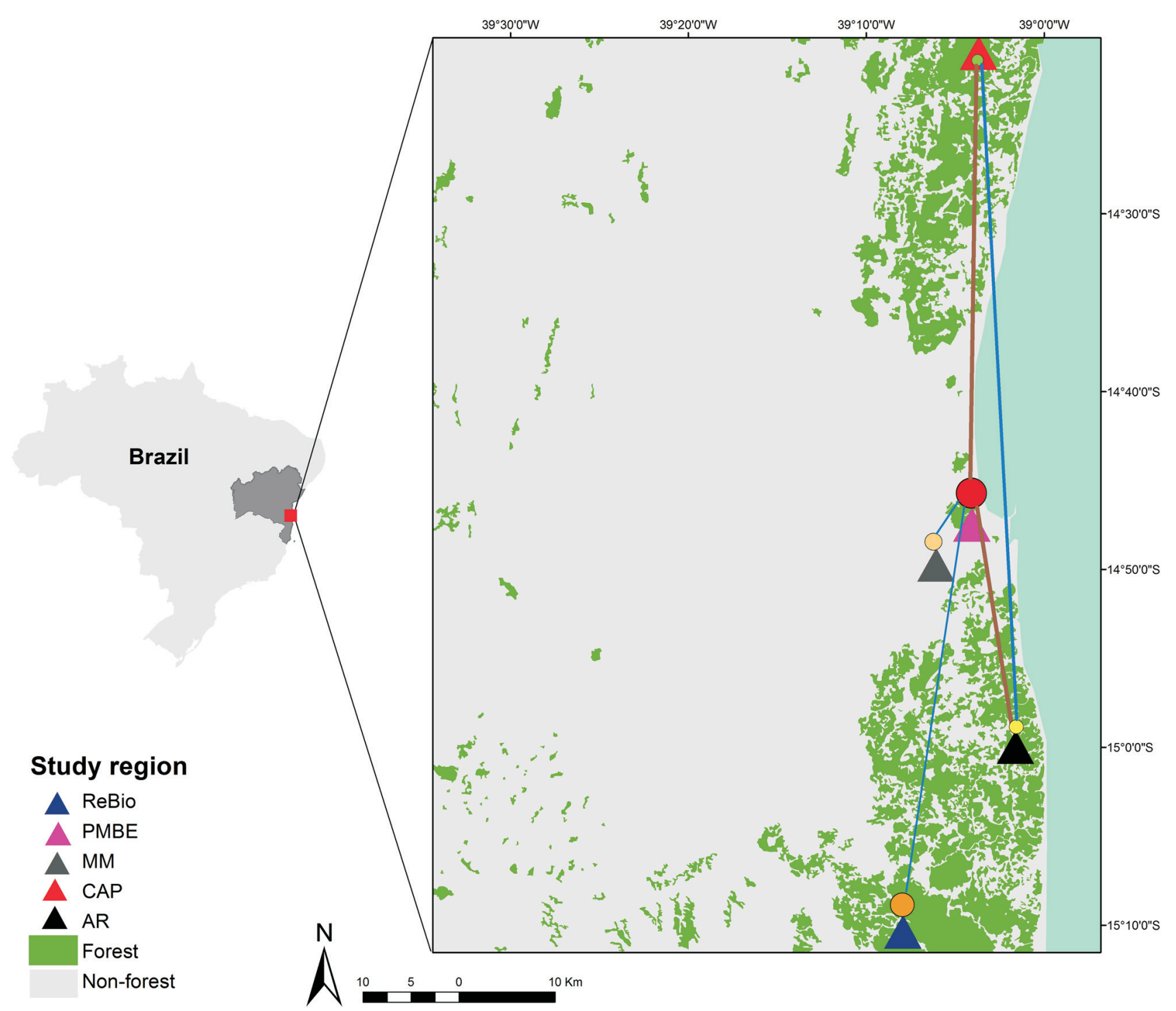

Figure 1 - Map of Brazil. The state of Bahia is highlighted, indicating the region of the study, with the current forest cover. Blue and brown lines show network linkages identified by EDENetworks (Kivelä et al., 2015) between nodes (sampling sites), using cpSSR markers. Line thickness is proportional to linkage strength and node size is proportional to the number of haplotypes for each sampling sites de E. ovata. Map data: Atlas of the Atlantic Forest remnants of the year 2016, obtained from SOS Mata Atlântica.

It consisted of an initial denaturation step at $94^{\circ} \mathrm{C}$ for $1 \mathrm{~min}$ followed by 30 cycles of an denaturation step at $94{ }^{\circ} \mathrm{C}$ for 1 min, annealing step at the specific annealing temperature for $45 \mathrm{~s}$, and extension step at $72{ }^{\circ} \mathrm{C}$ for $1 \mathrm{~min}$; 8 cycles for M13 tail amplification at $94{ }^{\circ} \mathrm{C}$ for $1 \mathrm{~min}, 53{ }^{\circ} \mathrm{C}$ for $45 \mathrm{~s}$, and $72^{\circ} \mathrm{C}$ for $1 \mathrm{~min}$; followed by a final extension step at 72 ${ }^{\circ} \mathrm{C}$ for $10 \mathrm{~min}$. The amplified fragments were subjected to capillary electrophoresis in a multiload system using an ABI 3500 genetic analysis (Applied Biosystems). Peaks were analyzed using GeneMarker software 2.6.2 (SoftGenetics, State College, PA, USA).

Ten loci were amplified in all sampled individuals (75 trees) from the five subpopulations (ReBio, MM, Cap, and AR) using chloroplastidial microsatellites (cpSSR) (Weising and Gardner, 1999) with an M13 tail and respec- tive tail fluorophores (6FAM, VIC, NED, and PET, Applied Biosystems). Amplifications were performed by PCR in Life Pro, 96, gradient thermal cycler (TC-96/G/H (B) A) Bioer Technology, Tokyo, Japan). The final concentration of PCR reagents in $13 \mu \mathrm{L}$ was: $0.75 \mathrm{ng} \mathrm{L}^{-1}$ of genomic DNA; $0.325 \mathrm{mM}$ of each dNTP (Invitrogen, Carlsbad, CA, USA); 1.3X PCR buffer (Invitrogen); $4.0 \mathrm{mM} \mathrm{MgCl}_{2} ; 0.325$ $\mathrm{mg} \mu \mathrm{L}^{-1} \mathrm{BSA}$ (Invitrogen); $0.2 \mathrm{mM}$ forward primer with the M13 tail; $0.4 \mathrm{mM}$ reverse primer; $0.06 \mathrm{mM}$ M13 complementary primer with the fluorophore; $1 \mathrm{U}$ Taq DNA polymerase (Invitrogen), and MilliQ water to complete the final volume. PCR was performed under the following conditions: denaturation at $94^{\circ} \mathrm{C}$ for 2 min followed by 30 cycles of denaturation at $94^{\circ} \mathrm{C}$ for $1 \mathrm{~min}$, annealing over a temperature gradient of $48^{\circ} \mathrm{C}$ to $62^{\circ} \mathrm{C}$ for each primer pair for 1 
min, and extension at $72^{\circ} \mathrm{C}$ for $1 \mathrm{~min}$. The second PCR step was programmed for 8 cycles as follows: denaturation at 94 ${ }^{\circ} \mathrm{C}$ for $1 \mathrm{~min}$, annealing at $53{ }^{\circ} \mathrm{C}$ (specified for the tail primers) for $1 \mathrm{~min}$, extension at $72^{\circ} \mathrm{C}$ for $1 \mathrm{~min}$, and final extension at $72{ }^{\circ} \mathrm{C}$ for $7 \mathrm{~min}$. Genotyping of the PCR products was performed on a multiload system (ABI 3130xl, Applied Biosystems), and GSLIZ500 was used as a size fragment standard (Applied Biosystems). To analyze the electropherograms and obtain the genotypes, GeneMarker version 2.2.0 software was used.

\section{Analysis of nuclear microsatellite markers (nSSR) and population genetics}

To calculate the alleles per locus (A), probability of exclusion of paternity (Q), and identity index (I), we used the CERVUS 3.0.6 program (Kalinowski et al., 2007). We used the divBasic function in the diveRsity package in the $\mathrm{R}$ software (Keenan et al., 2013) to calculate allelic richness, expected heterozygosity $\left(\mathrm{H}_{\mathrm{E}}\right)$, observed heterozygosity $\left(\mathrm{H}_{\mathrm{O}}\right)$, and inbreeding coefficient $(f)$. The confidence interval of $\mathrm{H}_{\mathrm{E}}, \mathrm{H}_{\mathrm{O}}$, and $f$ at $95 \%$ was calculated using divBasic function with 10,000 bootstraps. To plot the results of these analysis, the ggplot2 package was used in $\mathrm{R}$ software (Wickham, 2010).

Analysis of molecular variance (AMOVA) was conducted using GenAlex 6.5 (Peakall and Smouse, 2012). To evaluate the genetic structure of the subpopulations analyzed, we calculated $\mathrm{F}_{\mathrm{ST}}$ using the divBasic function of the diveRsity package (Keenan et al., 2013) and discriminant analysis of principal components (DAPC) (Jombart et al., 2010) using the Adegenet 2.0.0 package in $\mathrm{R}$ software (Jombart et al., 2008). To calculate the $95 \%$ confidence interval of the $\mathrm{F}_{\mathrm{ST}}$ with 10,000 bootstraps, we used the divBasic function in the diveRsity package in $\mathrm{R}$ software. Posteriorly, to determine if the geographic distance $(\mathrm{km})$ influenced the genetic distance between populations $\left(\mathrm{F}_{\mathrm{ST}}\right)$, simple linear regression analysis was performed in R software (http://www.r-project.org/). To identify the number of clusters, we used the find.clusters function, retaining all main components, and the best fit cluster number was inferred through the Bayesian information criterion (BIC), selecting the lowest BIC as the ideal cluster. To describe the relationships between the identified clusters, the generic function DAPC was used, retaining the number of principal components that incorporated $80 \%$ of the cumulative variance (PCA eigenvalues) and number of discriminant functions (DA eigenvalues) to maximize variation between groups. In the graphical representation of the results obtained in DAPC analysis, we used the scatter function to assign individuals to clusters according to their gene pool and compoplot function to produce a diagram representing the genetic pool of the individuals associated with clusters of the subpopulations.

\section{Population genetic analysis with chloroplastid microsatellite markers (cpSSR)}

To analyze the cpSSR loci, we used Haplotype Analysis software version 1.04 (Eliades and Eliades, 2009) to calculate the following genetic parameters: number of haplotypes $\left(\mathrm{N}_{\mathrm{H}}\right)$, number of unique haplotypes $\left(\mathrm{P}_{\mathrm{H}}\right)$, number of effective haplotypes $\left(\mathrm{H}_{\mathrm{Ne}}\right)$, haplotype richness $(\mathrm{H})$, haplotypic diversity $\left(\mathrm{H}_{\mathrm{E}}\right)$, total genetic differentiation $\left(\mathrm{F}_{\mathrm{ST}}\right)$ between areas, and average genetic distance between individuals $\left(\mathrm{D}^{2} \mathrm{sh}\right)$. Linear regression analysis was performed in R software (http://www.r-project.org/) to detect associations between the pairwise genetic $\left(\mathrm{F}_{\mathrm{ST}}\right)$ and geographical distances $(\mathrm{km})$.

To verify the existence of genetic bottlenecks in the subpopulations, we conducted the Wilcoxon test in software BOTTLENECK version 1.2.02 02 (Cornuet and Luikartt, 1996). As recommended for studies with few individuals per population and few loci ( $<20$ loci), the Wilcoxon test with the infinite allele model (IAM), stepwise mutation model (SMM), and two-phase model (TPM), which allows multiple-step mutations, were applied (Piry et al., 1999). For the TPM model, the proportion of SMM in TPM = 0.000 and variance of the geometric distribution for TPM $=$ 0.36 , corresponding to the most sensitive values for most microsatellites (Piry et al., 1999).

To visualize and analyze the genetic relationships without assuming a priori a cluster of individuals or populations, we used the EDENetworks program (Kivelä et al., 2015). Network analysis consisted of nodes (individuals or populations) linked according to their genetic relationships. While constructing networks of subpopulations and individuals, automatic thresholding was used. Automatic thresholding was detected by EDENetwork using the percolation threshold. The automatic thresholding used for network analysis was slightly below the percolation threshold so that the network remained connected. In the network at the subpopulation level, $\mathrm{F}_{\mathrm{ST}}$ was used as distance with the automatic threshold (0.42). In the network at the individual level, allele sharing was used as a distance with automatic thresholding (0.14).

\section{Results}

\section{Development of nSSR for E. ovata and population analysis}

We developed 13 new nuclear primer pairs for $E$. ovata which had (i) an average of 5.6 alleles, (ii) $\mathrm{H}_{\mathrm{O}}$ of $0.214-1.000$, (iii) $\mathrm{H}_{\mathrm{E}}$ of $0.198-0.878$, and (iv) a fixation in$\operatorname{dex}(\mathrm{F})$ of - $0.333-0.4763$ (see Tables S1 and S2). The combined probability of exclusion (Q) of these 13 loci was 0.9 $10^{-9}$ and identity index (I) was $328^{-10}$. The sequence, allele amplitude, and annealing temperature for each primer are shown in Table S1.

Population analysis verified that the 13 loci had similar distributions of allelic frequencies, average number of 
alleles, frequency of informative alleles, and estimated genetic diversities (Figures S1 and S2). The four subpopulations showed low numbers of effective alleles (AR = 2.610; $\mathrm{MM}=2.883 ;$ Cap $=2.685 ;$ ReBio $=2.841)$, low allelic richness (Figure 2), and private alleles in all subpopulations $(\mathrm{AR}=8, \mathrm{MM}=5, \mathrm{Cap}=4$ and $\mathrm{ReBio}=2)$. The observed heterozygosity (Ho) values were moderate to high (Figure 3). However, the Ho values were always higher than the expected heterozygosity (Figure 3), which was reflected by the negative values of the inbreeding coefficient (Figure 4) and significant genetic bottleneck in the four subpopulations (Table 1).

In contrast, in AMOVA, there were observed variances of $18 \%$ within and $80 \%$ among individuals, while there was only $2 \%$ variance among subpopulations. $F_{\text {ST }}$ analysis revealed that subpopulations showed low and non-significant genetic differentiation (Figure 5), despite the relatively large distances between some subpopulations (up to $89 \mathrm{~km}$ ).

We verified that geographic distance did not explain the pattern of genetic distance between subpopulations, as these factors were not significantly correlated $\left(\mathrm{R}^{2}=0.207\right.$, $p=0.36)$. DAPC revealed that for the four sampling areas form three genetic clusters $(\mathrm{K}=3, \mathrm{BIC}=66.06)$, a group was formed by MM and ReBio and the other two groups formed separately in areas AR and CAP (Figure 6A), with sharing of the gene pool between groups (Figure 6B).

\section{Population analysis for $E$. ovata using cpSSR}

Seven of the $10 \mathrm{cpSSR}$ primers tested in E. ovata were successfully amplified. Three were monomorphic (cpSSR1, cpSSR3, and cpSSR7) and four were polymorphic (cpSSR2, cpSSR4, cpSSR5, and cpSSR6), with an average of three alleles per locus and 14 haplotypes. Of these haplotypes, four were found exclusively in PMBE (H1, H8, $\mathrm{H} 9$, and H14), two were exclusively found in ReBio (H3 and H4), one in AR (H5), and another was exclusively found in Cap (H11). In contrast, six of the 14 haplotypes (H2, H6, H7, H10, H12, and H13) were shared by two or more study areas. Dominance of the four haplotypes $(\mathrm{H} 10$, $\mathrm{H} 6, \mathrm{H} 3$, and $\mathrm{H} 13$ ) was observed in these areas, with $80 \%$ of the analyzed individuals presenting only four maternal origins (Table S3). In intra-population analysis, we detected an average of five haplotypes. The PMBE subpopulation contained the highest number (7) of haplotypes, while the RPPN Cap subpopulation had the lowest (3) (Table 2). When we analyzed the number of effective haplotypes, the five areas showed an average of 2.32, representing approximately half of the average number of haplotypes found. These subpopulations showed, on average, low richness (4) and haplotype diversity (0.55), with low genetic distances between individuals (0.70). Overall, the highest levels of genetic diversity were found in PMBE and ReBio (Table 2).

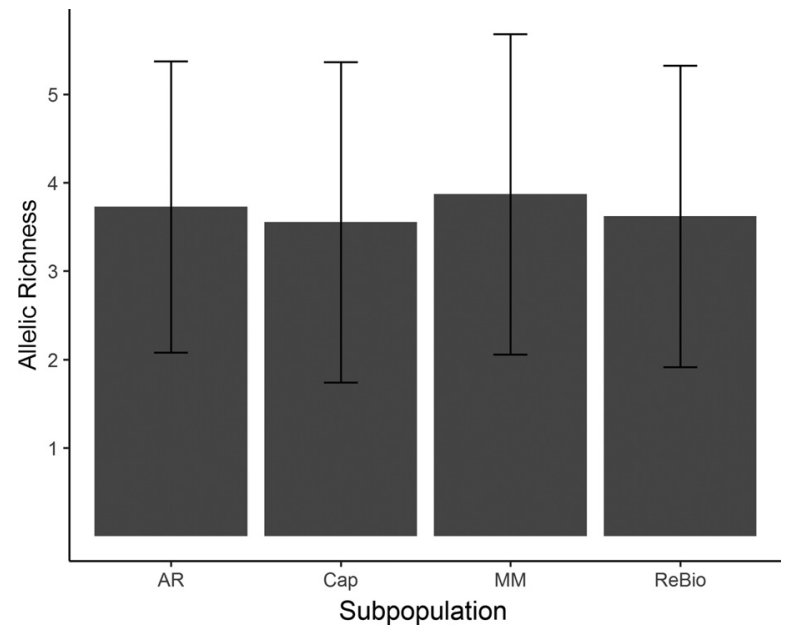

Figure 2 - Allelic richness with standard deviation values for E. ovata subpopulations with nSSR markers.

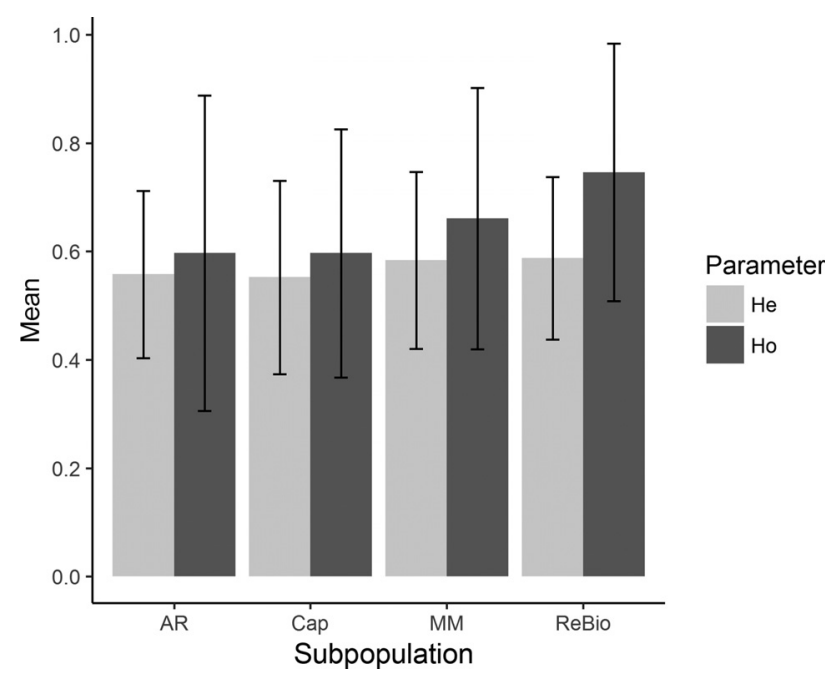

Figure 3 - Observed heterozygosity (Ho) and expected heterozygosity (He) with standard deviation values for E. ovata subpopulations with nSSR markers.

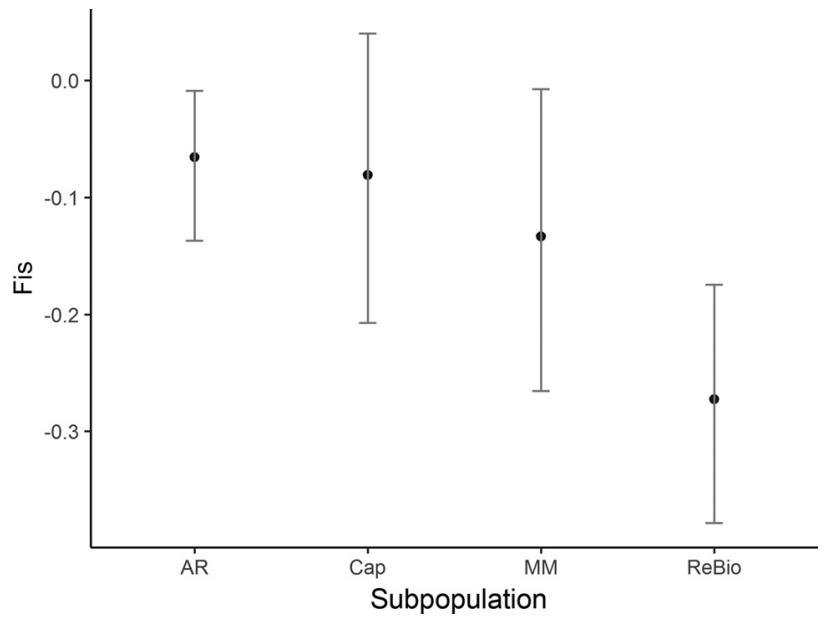

Figure 4 - Fixation index (Fis) estimated values with nSSR markers and $95 \%$ confidence intervals based on 10.000 bootstrap values for E. ovata subpopulations with nSSR markers. 
Table 1 - Wilcoxon test for E. ovata subpopulations with nSSR markers

\begin{tabular}{lccc}
\hline Subpopulation & IAM & TPM & SMM \\
\hline AR & $0.04016^{*}$ & 0.55371 & 0.77258 \\
Rebio & $0.00012 *$ & $0.00201^{*}$ & $0.05493 *$ \\
MM & $0.00153^{*}$ & 0.07324 & 0.34241 \\
Cap & $0.00085^{*}$ & 0.07324 & 0.24866 \\
\hline
\end{tabular}

Note: $\mathrm{AR}=$ Restinga; $\mathrm{ReBio}=$ Reserva Biológica de Una; $\mathrm{MM}=\mathrm{RPPN}$ Mãe da Mata; $P M B E=$ Parque Municipal Boa Esperança; Cap= RPPN capitão; Infinite Allele Model (IAM), Stepwise Mutation Model (SMM), and Two Phase Model (TPM). *represents significance at alpha $\leq 0.05$.

When we assessed the partitioned genetic diversity, we observed low levels of total genetic diversity (HT) and, consequently, low levels within subpopulations (HS), with higher values in PMBE and ReBio than in the other locations (Figure 7). Additionally, diversity due to genetic differentiation $\left(\mathrm{D}_{\mathrm{ST}}\right)$ was low in all subpopulations, with the lowest value in PMBE (Figure 7).

$\mathrm{F}_{\mathrm{ST}}$ analysis revealed that subpopulations had low genetic differentiation (Table 3), despite the relatively large distances between some subpopulations (up to $89 \mathrm{~km}$ ).

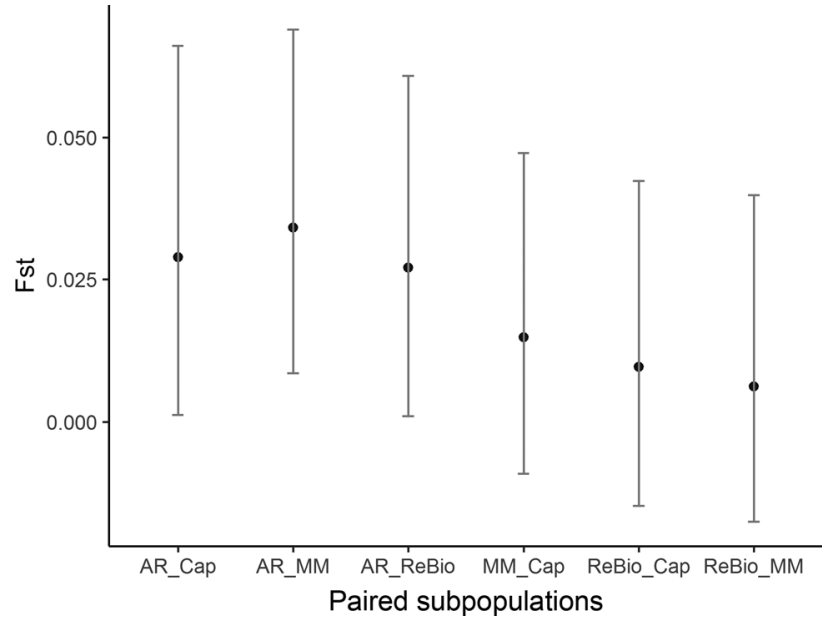

Figure 5 - $\mathrm{F}_{\mathrm{ST}}$ estimated values with nSSR markers and 95\% confidence intervals based on 10.000 bootstrap values of $E$. ovata sampled in four subpopulations.

Thus, geographic distance did not explain the pattern of genetic distance between subpopulations, as these factors were not significantly correlated $\left(\mathrm{R}^{2}=0.08, p=0.43\right)$. In network analysis at the population level, sharing of the gene
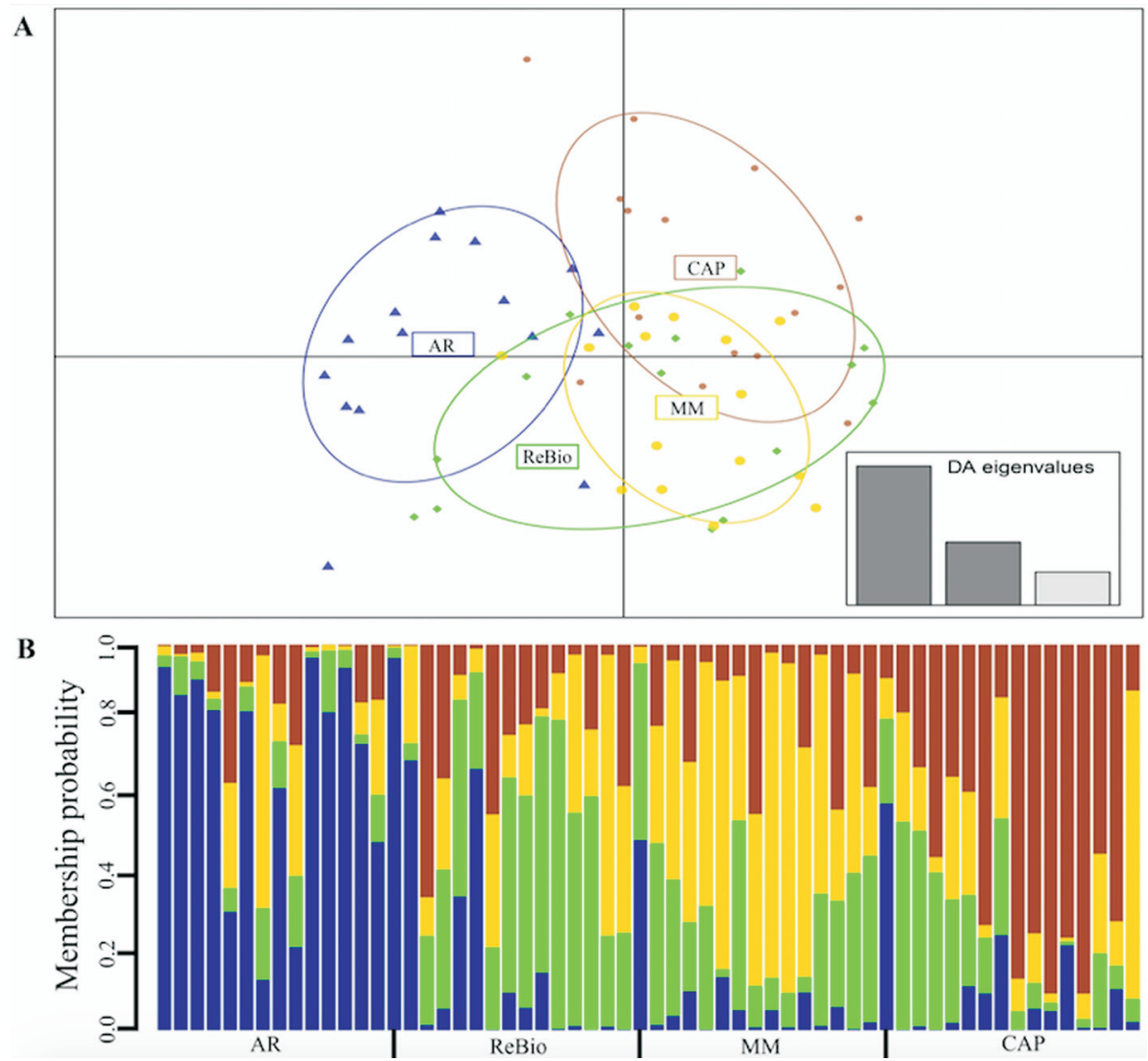

Figure 6 - Genetic differentiation among the four E. ovata subpopulations based on nSSR markers. A) The graph represents the individuals as dots and the subpopulations as ellipses according to their original groups, which model $95 \%$ of the corresponding variability plotted. The subpopulations (ellipses) are plotted within the orthogonal space defined by the first two eigenvalues of the PCA (inserts). B) Diagram representing the gene pool of the individuals associated with each of the subpopulations. Each vertical bar represents an individual with the height of the column segments showing the probability of being assigned to one of the four subpopulations. Dark lines correspond to the collection location. 
Table 2 - E. ovata subpopulation genetic parameters based on the cpSSR markers.

\begin{tabular}{|c|c|c|c|c|c|c|c|c|c|}
\hline Subpopulation & PA & $\mathrm{AH}$ & $\mathrm{N}$ & $\mathrm{N}_{\mathrm{H}}$ & $\mathrm{P}_{\mathrm{H}}$ & $\mathrm{H}_{\mathrm{Ne}}$ & $\mathrm{H}_{\mathrm{R}}$ & $\mathrm{H}_{\mathrm{E}}$ & $\mathrm{D}^{2} \mathrm{sh}$ \\
\hline AR & Not & - & 15 & 4 & 1 & 2.273 & 3 & 0.600 & 0.163 \\
\hline MM & Sustainable use & 13 & 15 & 5 & 0 & 1.800 & 4 & 0.476 & 0.147 \\
\hline CAP & Sustainable use & 660 & 15 & 3 & 1 & 1.316 & 2 & 0.257 & 0.041 \\
\hline ReBio & Integral protection & 11,400 & 15 & 6 & 2 & 2.528 & 5 & 0.648 & 0.463 \\
\hline PMBE & Integral protection & 437 & 15 & 7 & 4 & 3.689 & 6 & 0.781 & 2.707 \\
\hline Mean & - & - & 15 & 5 & 1.6 & 2.321 & 4 & 0.552 & 0.704 \\
\hline
\end{tabular}

Note: $\mathrm{PA}=$ Protected area; $\mathrm{AH}=$ Amount of hectares; $\mathrm{N}=$ Number of individuals per population; $\mathrm{N}_{\mathrm{H}}=$ Number of haplotypes; $\mathrm{P}_{\mathrm{H}}=$ Number of unique haplotypes; $\mathrm{H}_{\mathrm{Ne}}=$ Number of effective haplotypes; $\mathrm{H}_{\mathrm{R}}=$ Haplotypes richness; $\mathrm{H}_{\mathrm{E}}=$ Haplotype diversity; $\mathrm{D}^{2}$ sh= Average genetic distance between individuals; $\mathrm{AR}=$ Restinga; ReBio= Reserva Biológica de Una; MM= RPPN Mãe da Mata; PMBE= Parque Municipal Boa Esperança; Cap= RPPN capitão.

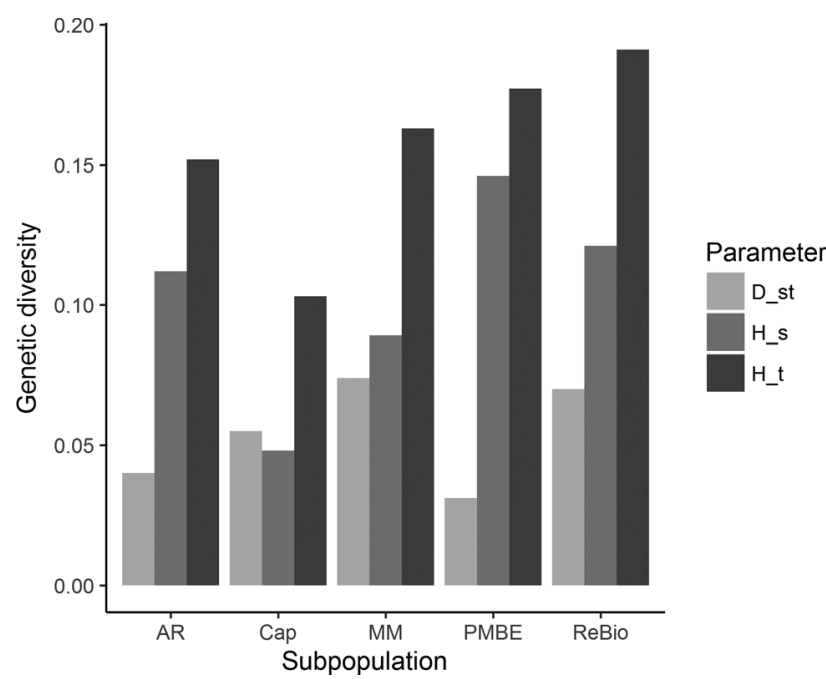

Figure 7 - Genetic diversity partitioned from the E. ovata subpopulations with cpSSR markers. $\mathrm{H}_{\mathrm{S}}=$ Genetic diversity within the population; $\mathrm{D}_{\mathrm{ST}}=$ Diversity due to genetic differentiation; $\mathrm{H}_{\mathrm{T}}=$ Total genetic diversity.

Table 3 - Genetic structure analysis $\left(\mathrm{F}_{\mathrm{ST}}\right)$ with cpSSR markers between areas in pairs in the lower diagonal and geographic distance in upper diagonal $(\mathrm{km})$.

\begin{tabular}{lccccc}
\hline & AR & ReBio & MM & Cap & PMBE \\
\hline AR & - & 24 & 16 & 67 & 21 \\
ReBio & 0.046 & - & 37 & 89 & 43 \\
MM & 0.060 & 0.052 & - & 52 & 6 \\
Cap & 0.013 & 0.079 & 0.092 & - & 46 \\
PMBE & 0.005 & 0.035 & 0.036 & 0.015 & - \\
\hline
\end{tabular}

Note: $\mathrm{AR}=$ Restinga; $\mathrm{ReBio}=$ Reserva Biológica de Una; $\mathrm{MM}=\mathrm{RPPN}$ Mãe da Mata; $\mathrm{PMBE}=$ Parque Municipal Boa Esperança; $\mathrm{Cap}=\mathrm{RPPN}$ capitão.

pool was observed, reflecting the connection between subpopulations (Figure 1) and a substructure between individuals, forming two groups (gray and green) that shared alleles between individuals from different subpopulations (Figure 8).

\section{Discussion}

We detected gene pool sharing among forest remnants by an insect-pollinated, animal-dispersed widely distributed tree in the Atlantic Forest. This information is important for recovering degraded areas, mainly in PAs. We also determined the relevance of integrating such important remnants in Atlantic Forest management plans, as suggested by ecological corridors projects in the region. Considering the difficulties of managing protected areas in Brazil because of the lack of knowledge about biodiversity in PAs (Oliveira et al., 2017), conservation genetics can help public managers make decisions to maximize the potential of PAs in maintaining diversity and genetic connections between these areas and with surrounding forest remnants (Torres-Florez et al., 2017).

The new set of nSSR markers developed for E. ovata showed polymorphisms sufficient for individual identification and kinship analysis, providing an excellent molecular tool for population genetic studies. Additionally, we demonstrated that the 15 individuals sampled and genotyped with 13 loci represented the number of alleles and frequency of informative alleles and genetic diversity of each of the four subpopulations. This small number of individuals may have been sufficient for population genetic analysis because geographically distant individuals were sampled within each subpopulation. Another important factor is that loci with high heterozygosity and a similar distribution of allelic frequency may enable genetic studies with reduced sample sizes (Hale et al., 2012). Thus, this set of tools will be useful for subpopulation studies by providing access to information on the genetic variability of E. ovata; additionally, these data can be used to develop alternative strategies for managing and conserving tree species in the Atlantic Rainforest.

Genetic diversity assessment using the cpSSR marker revealed that the five subpopulations sampled have few haplotypes, with a large proportion of individuals (80\%) showing only four haplotypes. This finding suggests that these subpopulations of E. ovata in the ecological corridor of the Atlantic Forest in southern Bahia were mainly founded by four maternal lineages, reflecting a small vari- 


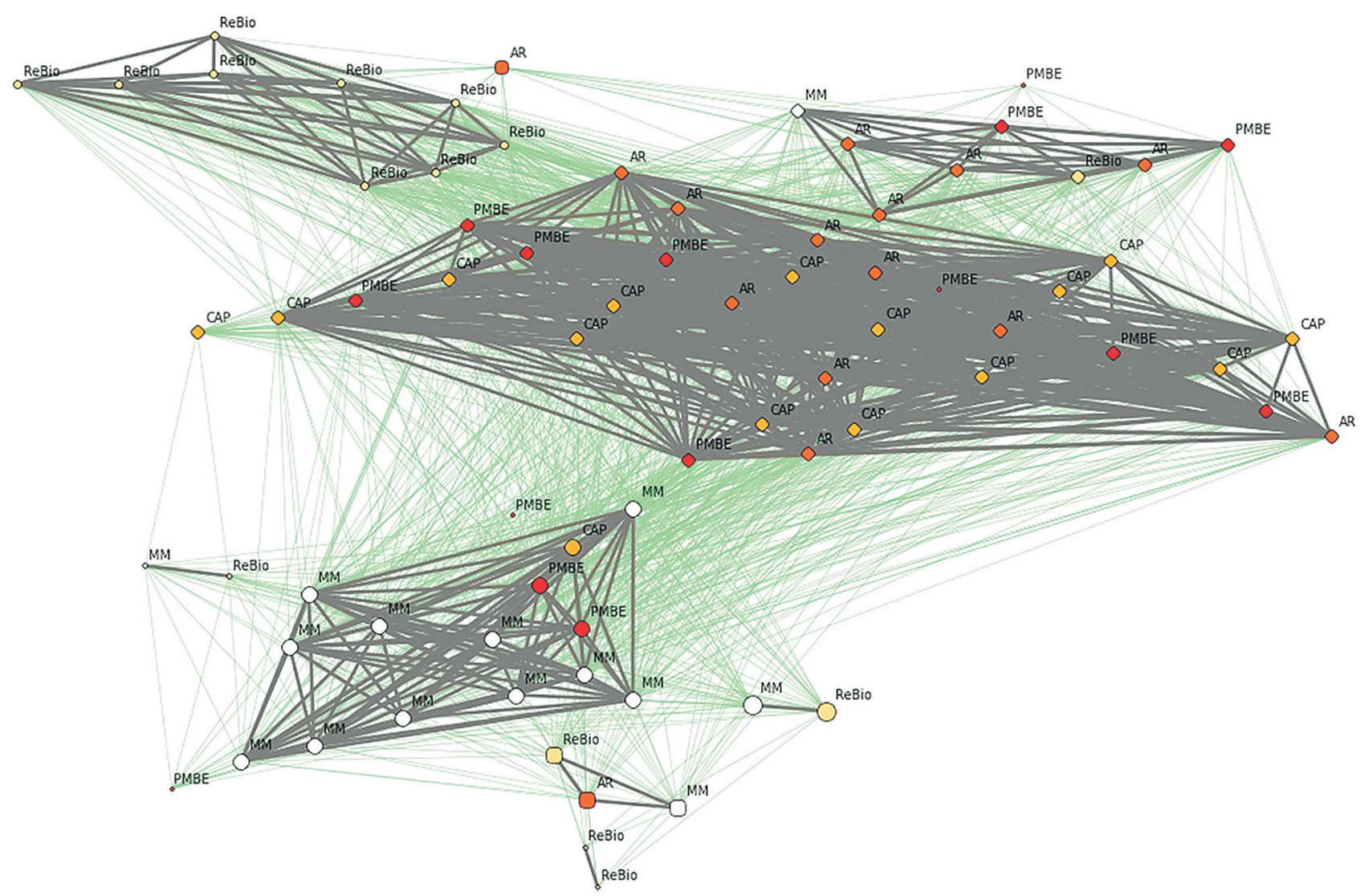

Figure 8 - Network analysis among the individuals of $E$. ovata with cpSSR markers. Gray and green lines show network linkages identified by EDENetworks (Kivelä et al., 2015) between nodes (individuals). The colors of the nodes represent the sampling sites, the line thickness is proportional to linkage strength and node size is proportional to the number of linkages for each node.

ety of seed sources and strong founding effect, or a recent genetic bottleneck (Parducci et al., 2001; Logossa et al., 2011; Li et al., 2012; Wang, 2013). In contrast, the presence of unique haplotypes in the different subpopulations reflects the importance of the areas for maintaining genetic variability, particularly the integral protection area (PMBE and ReBio) that contains six of the eight unique haplotypes.

Intrapopulational analysis showed that E. ovata subpopulations have low average haplotypic diversity compared to other plants species (Petit et al., 2005). Additionally, these populations have a low number of effective haplotypes and low haplotypic richness, reflecting the low genetic distance among individuals (Wang et al., 2011; Wójkiewicz and Wachowiak, 2016). These results may be a consequence of the narrow genetic base of individuals that founded the subpopulations or a genetic bottleneck, reinforcing the importance of maintaining functional connectivity through gene flow between these subpopulations, as they may be more sensitive to external disturbances and prone to genetic drift (Parducci et al., 2001; Martins et al., 2011; Tong et al., 2013). Taking into account the critical state of fragmentation and reduction of the Atlantic Forest (Ribeiro et al., 2009), one method of maintaining contemporary gene flow is by managing regional land use to produce a heterogeneous mosaic (e.g., through ecological corridors or step-stones between forest remnants) (Fonseca et al., 2004; Damschen et al., 2006; Brudvig et al., 2009).

The four subpopulations evaluated with the nSSR loci showed genetic diversity $\left(\mathrm{H}_{\mathrm{E}}\right.$ and $\left.\mathrm{H}_{\mathrm{O}}\right)$ estimates similar to those found in rare and overexploited palm and tree species from the Atlantic Forest in southern Bahia, such as Euterpe edulis Mart. $\left(\mathrm{H}_{\mathrm{E}}=0.64\right.$ and $\left.\mathrm{H}_{\mathrm{O}}=0.58\right)$ and Melanoxylon brauna Schott $\left(\mathrm{H}_{\mathrm{E}}=0.57\right.$ and $\left.\mathrm{H}_{\mathrm{O}}=0.53\right)$ (Borges et al., 2014; Santos et al., 2015). However, these diversity indices are low compared to those of other more abundant species in the same environment, such as Licania hypoleuca Benth. $\left(\mathrm{H}_{\mathrm{E}}=0.84\right.$ and $\left.\mathrm{H}_{\mathrm{O}}=0.71\right)$ (França et al., 2015). It is also important to emphasize that the $\mathrm{H}_{\mathrm{O}}$ of E. ovata was larger than the $\mathrm{H}_{\mathrm{E}}$, indicating an imbalance between evolutionary forces, such as inbreeding or genetic bottleneck. Notably, inbreeding $(f)$ values were negative in all subpopulations, strongly indicating that preferential crosses occurred between unrelated individuals. We used the Wilcoxon test to evaluate whether this excess in $\mathrm{H}_{O}$ was also the result of a genetic bottleneck in E. ovata subpopulations. The genetic bottleneck may cause the development of an excess of transient heterozygosity after a recent change in the effective 
population size when heterozygotes have a selective advantage, resulting in a higher $\mathrm{H}_{\mathrm{O}}$ than $\mathrm{H}_{\mathrm{E}}$ (Cornuet and Luikartt, 1996). The four subpopulations evaluated showed excess heterozygosity because of a genetic bottleneck, as revealed by the IAM. As demonstrated by Cornuet and Luikartt, (1996), the IAM is a more sensitive model for detecting the genetic bottleneck than the SMM and TPM models, indicating that the nSSR loci of E. ovata satisfied the requirements of the infinite allele model.

The results obtained with the two sets of markers (nSSR and cpSSR) showed convergence, with the results of AMOVA (nSSRs) and haplotype diversity analysis (cpSSR) revealing that diversity within the subpopulations contributed more to the overall composition than genetic variation among the subpopulations. This is likely the consequence of allele sharing and ancestral haplotype lineages that founded these populations (Wang, 2013). Additionally, areas of integral protection may play an important role in maintaining genetic variability. Human interference is prohibited in these areas, which may have favored the maintenance of unique haplotypes and alleles (Bruner et al., 2001). Another interesting point is that although the differences were small, the areas of integral protection (ReBio and PMBE), showed the largest genetic indices compared to the other areas. The lowest genetic indices observed in the two sustainable use PAs may reflect the selective logging of E. ovata in RPPN Cap and forest reduction in RPPN $\mathrm{MM}$, which both had anthropogenic impacts before the implementation of PAs (personal communication from the land owners). Genetic variability plays an important role in natural selection by maintaining the ability of populations to adapt to their habitats over time (Leimu and Fischer, 2008). Even small losses of genetic variability require attention, particularly in the subpopulation of Restinga (AR) that is outside the conservation unit and, consequently, more susceptible to human impact and the loss of alleles and haplotypes.

Genetic structure analysis $\left(\mathrm{F}_{\mathrm{ST}}\right)$ revealed that the studied subpopulations exhibited very low genetic structuring when analyzed with both markers, and this genetic pattern was not influenced by geographic distance. However, DAPC analysis revealed that the four collection areas formed three genetic clusters. However, many individuals from an a priori subpopulation are inserted into ellipses of other subpopulations, and there are overlaps of ellipses between subpopulations, supporting the observed low $\mathrm{F}_{\mathrm{ST}}$ values. Additionally, there is a large mixture of the gene pool in individuals of different clusters, reinforcing the results obtained in $\mathrm{F}_{\mathrm{ST}}$ analysis and showing that genetic diversity is mainly contained among individuals, as indicated by AMOVA.

Network analysis revealed a substructure between individuals, with two groups (green and gray), formed by individuals from different subpopulations. Importantly, the connections between individuals from the two groups dem- onstrated that although the individuals belonged to a specific group (green or gray), they also had genetic similarities with individuals from the other group. Thus, although two groups were observed, they are genetically connected, which may reflect allele sharing among individuals in these groups. Overall, the same patterns in the results were observed by DAPC (nSSR), network analysis (cpSSR), and Fst analyses with both markers revealing that these subpopulations are functionally connected by the dispersion of pollen and seeds. However, even with gene pool sharing, it is possible that gene flow among these subpopulations is currently impaired because of fragmentation of the forest in this specific landscape (see details in Figure 1). However, additional studies evaluating contemporary gene flow are needed to evaluate this issue. Furthermore, large infrastructure projects of the Brazilian government, such as construction of the southern port and the west-east railroad, may negatively impact some of the study areas (mainly PMBE and Cap), causing suppression and forest fragmentation and showing great potential for disorderly urban expansion. It is important to consider in the context of conservation during regional planning that these remnants of the Atlantic Forest maintain functional (genetic) connectivity. To implement efficient conservation strategies, we recommend that the five studied subpopulations should be considered as a single ecological entity during regional planning of different land uses.

\section{Acknowledgments}

The authors thank Mr. Ronaldo Santana; Instituto de Estudos Socioambientais do Sul da Bahia - IESB; Instituto Chico Mendes de Conservação da Biodiversidade ICMBio; and the Secretaria de Meio Ambiente de Ilhéus for the sampling licenses. They thank the Fundação de Amparo à Pesquisa do Estado da Bahia (FAPESB) for granting a scholarship to ASS; and Fapesb - Pronex (\#PNX0014/2009), and T Coordenação de Aperfeiçoamento de Pessoal de Nível Superior - Brasil (CAPES) - Finance Code 001, for financing the project and granting a scholarship to RT CAPES-PNPD (\#02736/09-8). The authors also thank the Brazilian National Council of Scientific and Technological Development (CNPq) for the FAG research productivity fellowship.

\section{Conflict of Interest}

The authors declare no conflicts of interest.

\section{Author contributions}

ASS, RT and FAG conceived and designed the study; ASS, DBB, CVV, CVDB and PSR conducted the field and laboratory experiments; ASS and RT analyzed the data; ASS and FAG wrote the manuscript, all authors read and approved the final version. 


\section{References}

Benchimol M, Mariano-Neto E, Faria D, Rocha-Santos L, Pessoa MS, Sanches F, Custodio D and Cazetta E (2017) Translating plant community responses to habitat loss into conservation practices Forest cover matters. Biol Conserv 209:499-507.

Borges DB, Mariano-Neto E and Gaiotto FA (2014) Development of microsatellite primers for Melanoxylon brauna (Fabaceae): an endangered and endemic tree from the Brazilian Atlantic Forest. Conserv Genet Resour 7:65-68.

Brudvig LA, Damschen EI, Tewksbury JJ, Haddad NM and Levey DJ (2009) Landscape connectivity promotes plant biodiversity spillover into non-target habitats. Proc Natl Acad Sci U S A 106:9328-9332.

Bruner AG, Gullison RE, Rice RE and Fonseca GAB (2001) Effectiveness of parks in protecting tropical Biodiversity. 291:125-128.

Carvalho CS, Ribeiro MC, Côrtes MC, Galetti M and Collevatti RG (2015) Contemporary and historic factors influence differently genetic differentiation and diversity in a tropical palm Contemporary and historic factors influence differently genetic differentiation and diversity in a tropical palm. Heredity 115:216-224.

Carvalho CS, Ballesteros-Mejia L, Ribeiro MC, Côrtes MC, Santos AS and Collevatti RG (2017) Climatic stability and contemporary human impacts affect the genetic diversity and conservation status of a tropical palm in the Atlantic Forest of Brazil. Conserv Genet 18:467-478.

Cornuet JM and Luikartt G (1996) Description and power analysis of two tests for detecting recent population bottlenecks from allele frequency data. Genetics 144:2001-2014.

Corriveau JL and Coleman AC (1988) Rapid screening method to detect potential biparental inheritance of plastid DNA and results for over 200 angiosperm species. Am J Bot 75:1443-1458.

Damschen EI, Haddad NM, Orrock JL, Tewksbury JJ and Levey DJ (2006) Corridors increase Plant species richness at large scales. Science 313:1284-1286.

Doyle JJ and Doyle JL (1987) Isolation of plant DNA from fresh tissue. Focus 12:13-15.

Eliades NG and Eliades DG (2009) User's Manual HAPLOTYPE ANALYSIS Software for Analysis of Haplotype Data, https://www.researchgate.net/pro-

file/Nicolas_George_Eliades/publica-

tion/221936337_HAPLOTYPE_ANALYSIS soft-

ware_for_analysis_of_haplotype_data/links/5a09ab06a6fd cc8b54781453/HAPLOTYPE-ANALYSIS-software-for-a nalysis-of-haplotype-data.pdf

Fonseca GD, Alger K, Pinto LP, Araújo M and Cavalcanti R (2004) Corredores de biodiversidade: O corredor central da Mata Atlântica. Corredores ecológicos: uma visão integradora de ecossistemas. Ibama, Ministério do Meio Ambiente, Brasilia, pp 47-65.

França DDS, Neres J and Gaiotto FA (2015) Development and characterization of 26 microsatellite loci in Licania hypoleuca (Chrysobalanaceae) and transferability to Licania hoehnei. Biochem Syst Ecol 59:204-208.

Gaiotto FA, Grattapaglia D and Vencovsky R (2003) Genetic structure, mating system, and long-distance gene flow in Heart of Palm (Euterpe edulis Mart.). J Hered 94:399-406.
Hale ML, Burg TM and Steeves TE (2012) Sampling for microsatellite-based population genetic studies: 25 to 30 individuals per population is enough to accurately estimate allele frequencies. PloS One, 7:e45170.

Jombart T, Lyon D and Biome L De (2008) adegenet: A R package for the multivariate analysis of genetic markers. Bioinformatics 24:1403-1405.

Jombart T, Devillard S and Balloux F (2010) Discriminant analysis of principal components: A new method for the analysis of genetically structured populations. BMC Genet 11:94.

Kalinowski ST, Taper ML and Marshall TC (2007) Revising how the computer program CERVUS accommodates genotyping error increases success in paternity assignment. Mol Ecol. 16:1099-1106.

Keenan K, McGinnity P, Cross TF, Crozier WW and Prodohl PA (2013) diveRsity: An R package for the estimation and exploration of population genetics parameters and their associated errors. Methods Ecol Evol 4:782-788.

Kivelä M, Arnaud-Haond S and Saramäki J (2015) EDENetworks: A user-friendly software to build and analyze networks in biogeography, ecology and population genetics. Mol Ecol Resour 15:117-122.

Leimu R and Fischer M (2008) A meta-analysis of local adaptation in plants. PLoS One 3:e4010.

Li J, Jin Z and Tan T (2012) Genetic diversity and differentiation of Sinocalycanthus chinensis populations revealed by chloroplast microsatellite (cpSSRs) markers. Biochem Syst Ecol 41:48-54.

Lima MM and Mariano-Neto E (2014) Extinction thresholds for Sapotaceae due to forest cover in Atlantic Forest landscapes. Forest Ecol Manag 312:260-270.

Logossa ZA, Camus-Kulandaivelu L, Allal F, Vaillant A, Sanou H, Kokou K, Bouvet J and Bouvet JM (2011) Molecular data reveal isolation by distance and past population expansion for the shea tree (Vitellaria paradoxa) in West Africa. Mol Ecol 20:4009-4027.

Lorenzi H (1998) Árvores brasileiras: Manual de identificação e cultivo de plantas arbóreas nativas do Brasil. Plantarum, Nova Odessa, vol. 2.

Martini AMZ, Fiaschi P, Amorim AM and Paixão JL (2007) A hot-point within a hot-spot: A high diversity site in Brazil's Atlantic Forest. Biodivers Conserv 16:3111-3128.

Martins K, Chaves LJ, Vencovsky R and Kageyama PY (2011) Genetic structure based on nuclear and chloroplast microsatellite loci of Solanum lycocarpum A. St. Hil. (Solanaceae) in Central Brazil. Genet Mol Res 10:665-677.

MMA - Ministério do Meio Ambiente (2008) Experiências em implementação de corredores ecológicos /Ministério do Meio Ambiente. Secretaria de Biodiversidade e Florestas. Departamento de Áreas Protegidas. Programa Piloto para a Proteção das Florestas Tropicais do Brasil, Brasília, 80 pp.

Murray-Smith C, Brummitt NA, Oliveira-Filho ARYT, Bachman S, Moat J, Lughadha EMNIC and Lucas EVEJ (2008) Plant diversity hotspots in the Atlantic Coastal Forests of Brazil. Conserv Biol 23:151-163.

Myers N, Mittermeier RA, Mittermeier CG, Fonseca GAB and Kent J (2000) Biodiversity hotspots for conservation priorities. Nature 403:853.

Oliveira U, Soares-Filho BS, Paglia AP, Brescovit AD, Carvalho CJ, Silva DP and Stehmann JR (2017) Biodiversity conservation gaps in the Brazilian protected areas. Sci Rep 7:1-9. 
Pardini R, Bueno AA, Gardner TA, Prado PI and Metzger JP (2010) Beyond the fragmentation threshold hypothesis: Regime shifts in biodiversity across fragmented landscapes. PLoS One 5:13666.

Parducci L, Szmidt AE, Madaghiele A and Vendramin GG (2001) Genetic variation at chloroplast microsatellites (cpSSRs) in Abies nebrodensis (Lojac.) Mattei and three neighboring Abies species. Theor Appl Genet 102:733-740.

Peakall R and Smouse PF (2012) GenAlEx 6.5: Genetic analysis in Excel. Population genetic software for teaching and research - An update. Bioinformatics 28:2537-2539.

Pessoa MS, Rocha-Santos L, Talora DC, Faria D and MarianoNeto E (2016) Fruit biomass availability along a forest cover gradient. Biotropica 49:45-55.

Petit RJ, Duminil J, Fineschi S, Hampe A, Salvini D and Vendramin GG (2005) Comparative organization of chloroplast, mitochondrial and nuclear diversity in plant populations. Mol Ecol 14:689-701.

Piry S, Luikart G and Cornuet JM (1999) Computer note. BOTTLENECK: A computer program for detecting recent reductions in the effective size using allele frequency data. J Hered 90:502-503.

Ribeiro MC, Metzger JP, Martensen AC, Ponzoni FJ and Hirota MM (2009) The Brazilian Atlantic Forest: How much is left, and how is the remaining forest distributed? Implications for conservation. Biol Conserv 142:1141-1153.

Santos AS, Cazetta E, Morante Filho JC, Baumgarten J, Faria D and Gaiotto FA (2015) Lessons from a palm: Genetic diversity and structure in anthropogenic landscapes from Atlantic Forest, Brazil. Conserv Genet 16:1295-1302.

Santos AS, Cazetta E, Dodonov P, Faria D and Gaiotto FA (2016) Landscape-scale deforestation decreases gene flow distance of a keystone tropical palm, Euterpe edulis Mart (Arecaceae). Ecol Evol 6:6586-6598.

Tabarelli M, Cardoso Da Silva JM and Gascon C (2004) Forest fragmentation, synergisms and the impoverishment of neotropical forests. Biodivers Conserv 13:1419-1425.

Thomas WW, Garrison J and Arbela AL (1998) Plant endemism in two forests in southern Bahia, Brazil. Biodivers Conserv 7:311-322.

Tong Y, Wu C and Gao L (2013) Characterization of chloroplast microsatellite loci from whole chloroplast genome of $\mathrm{Ca}-$ mellia taliensis and their utilization for evaluating genetic diversity of Camellia reticulata (Theaceae). Biochem Syst Ecol 50:207-211.

Torres-Florez JP, Johnson WE, Nery MF, Eizirik E, OliveiraMiranda MA and Galetti Jr PM (2017) The coming of age of conservation genetics in Latin America: What has been achieved and what needs to be done. Conserv Genet 19:1-15.

Tóth EG, Vendramin GG, Bagnoli F, Cseke K and Höhn M (2017) High genetic diversity and distinct origin of recently fragmented Scots pine (Pinus sylvestris L.) populations along the Carpathians and the Pannonian Basin. Tree Genet Genomes 13:47

Untergasser A, Nijveen H, Rao X, Bisseling T, Geurts R and Leunissen JA (2007) Primer3Plus, an enhanced web interface to Primer3. Nucleic Acids Res 35(suppl 2):W71-W74.

Wang Y (2013) Chloroplast microsatellite diversity of Opisthopappus Shih (Asteraceae) endemic to China. Plant Syst Evol 299:1849-1858.

Wang Y, Guo J and Zhao G (2011) Chloroplast microsatellite diversity of Clintonia udensis (Liliaceae) populations in East Asia. Biochem Syst Ecol 39:22-30.

Weising K and Gardner RC (1999) A set of conserved PCR primers for the analysis of simple sequence repeat polymorphisms in chloroplast genomes of dicotyledonous angiosperms. Genome 42:9-19.

Wickham H (2010) ggplot2: Elegant graphics for data analysis. J Stat Softw 35:65-88.

Wójkiewicz B and Wachowiak W (2016) Substructuring of Scots pine in Europe based on polymorphism at chloroplast microsatellite loci. Flora 220:142-149.

Zhang X, Shi M, Shen D and Chen X (2012) Habitat loss other than fragmentation per se decreased nuclear and chloroplast genetic diversity in a monoecious tree. PLoS One 7:e39146.

\section{Supplementary material}

The following online material is available for this article: Table S1 - Characterization of the new 13 microsatellite loci specific to E. ovata.

Table S2 .. Characterization of 13 microsatellite loci in four subpopulations of E. ovata.

Tabie $\overline{\mathrm{S}} \overline{3}$ - Frequency of E. ovata haplotypes in the five study areas.

Figıre Si - Allele frequencies of the 13 nSSR loci in four subpopulations of E. ovata.

Figure $I$ - Mean allelic pattern with standard deviation of the $13 \mathrm{nSSR}$ loci in four subpopulations of E. ovata.

\section{Associate Editor: Dario Grattapaglia}

License information: This is an open-access article distributed under the terms of the Creative Commons Attribution License (type CC-BY), which permits unrestricted use, distribution and reproduction in any medium, provided the original article is properly cited. 